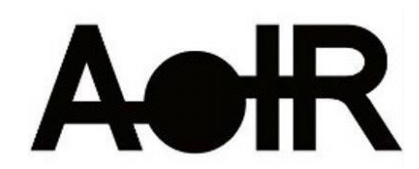

Selected Papers of \#AoIR2021:

The 22nd Annual Conference of the

Association of Internet Researchers

Virtual Event / 13-16 Oct 2021

\title{
BETWEEN INCLUSION \& EXCLUSION: THE DIGITAL LIVES OF UNDOCUMENTED IMMIGRANTS IN THE UNITED STATES
}

\author{
Zach Bastick \\ Oxford University \\ Marie Mallet \\ Oxford University
}

\section{Introduction}

There are approximately 10.3 to 10.7 million undocumented immigrants in the United States, approximately half of whom originate from Mexico (Connor et al., 2019). These individuals face distinct intersectional vulnerabilities, exclusion from many public institutions and services, and increased risks of exploitation (Mallet et al., 2017). Despite the heightened effects that digital inclusion may have on this precarious group, there is a paucity of research on their digital lives. This paper investigates their digital practices and attitudes, and the ways in which digital technologies reduce or reinforce their marginalization. It provides needed insight on digital life at the margins of society.

\section{Theoretical Framework}

Undocumented immigrants rely on digital technologies to facilitate risky border crossings (Newell et al., 2016), aid integration into host communities (Kaufmann, 2018), and grow social capital (Gonzales, 2017). However, these same technologies can surveil migrants' social networks and increase their risks of deportation (Wall et al., 2015). Undocumented Latino immigrants are likely to struggle with these privacy risks (Guberek et al., 2018). Yet, since undocumented Latino immigrants are often (deliberately) hard to reach, there is a paucity of evidence on the ways in which these immigrants use technology to mitigate their undocumented status.

Both digital inclusion and undocumented status are increasingly viewed in sociology and media studies as continuums rather than dichotomies. In recent years, the binary of the digital divide - that is, being on the 'right' or 'wrong side' of the gap in digital access, skills, and literacy - has been supplemented by the more nuanced notion of digital inclusion (Helsper, 2021). Likewise, the inclusion of undocumented immigrants, for

Suggested Citation (APA): Bastick, Z. and Mallet, M. (2021, October). Between Inclusion \& Exclusion: The Digital Lives of Undocumented Immigrants in the United States. Paper presented at AoIR 2021: The 22nd Annual Conference of the Association of Internet Researchers. Virtual Event: AolR. Retrieved from http://spir.aoir.org. 
example as essential workers during the COVID-19 pandemic, is recognized as being restricted by "varying degrees of subordination, rule, discrimination, and segmentation" (Mezzadra and Nielson 2013: 159). As such, De Genova (2013) writes of 'inclusion through exclusion', showing that 'illegalization' is a particular form of inclusion. The mismatch between their legal exclusion and their societal inclusion constitutes what Lamont (2018, p.412) has called a 'recognition gap'.

Recent studies in communication suggest that digital technologies can both attenuate and exacerbate dimensions of marginality (Pearce et al., 2020). For undocumented immigrants, this can lead to both positive and negative outcomes of digital inclusion (Bastick and Mallet, 2021). This vests marginalized individuals with the responsibilities of juggling these outcomes and their digital processes - rendering them both subjects and objects of complex technological dynamics that they are often ill-suited to direct.

\section{Method}

This paper reports interim findings from an original set of 44 semi-structured interviews with undocumented Latino immigrants, conducted in the United States between February and July 2021. Interviewees were recruited through snowball sampling based on an initial sample contacted through the authors' existing networks and connections with immigrant organizations. We constructed an interview guide covering pertinent themes: (1) digital access and skills; (2) attitudes towards digital technologies; (3) outcomes related to undocumented status; (4) impacts on transnational family practices; (5) privacy and attitudes towards government and corporate data collection; (6) attitudes towards Al (such as newsfeeds); (7) self-efficacy in detecting fake news; and (8) pandemic related impacts on digital inclusion. Our analysis was framed by constructivist grounded theory - enabling new findings to emerge from the data without being bound by the initial thematic frame (Charmaz, 2014). We report below on three of key findings.

\section{Key Findings}

\section{Digital employment and gig work}

Our interviewees reported using the internet to circumvent their legal inability to work in the United States. Craigslist, Facebook, and Yelp were crucial for finding employment in manual labor and service sector jobs. Conversely, we found that digital work opportunities sometimes reinforced the vulnerabilities of undocumented status: Many reported online employers disappearing before paying; Others had difficulty recovering from scams masquerading as job opportunities; and others noted that gig work apps enabled exploitative working conditions - e.g., working for reduced pay under an online food delivery account of a documented individual.

\section{Digital family and social practices}

Video calls and instant messaging (especially WhatsApp) were reported as being especially important for maintaining transnational family practices. Conversely, they sometimes unanchored identities - underscoring that some undocumented immigrants are both far from 'home' and not fully integrated in the US. Online relationships 
cultivated through apps or social media groups for immigrants was sometimes used to alleviate social exclusion. Importantly, with few exceptions, most did not substantially report modifying their online practices due to fears of surveillance by immigration services or the risks of deportation.

\section{Telehealth}

Being largely uninsured, many reported relying on digital family communication to obtain health guidance. A few reported relying on telehealth services abroad for support. Obtaining health information through online search engines was a common strategy to mitigate their lack of coverage in the US, yet many remained uncertain about the opportunities and risks associated with seeking care in the US.

\section{Conclusion}

Highly vulnerable populations are associated with specific sets of vulnerabilities that interact with their digital inclusion. As such, there is a need to understand how digital technologies alleviate, but also exacerbate, marginalization. Our analysis points to the utility of conceptualizing the digital inclusion of undocumented immigrants in terms of (a) fluid legal statuses, (b) involving different processes, and (c) resulting in differential outcomes. We underscore the need for more research on the digital lives of highly vulnerable populations, generally - and suggest that intersectionality and marginalization offer useful frameworks for such studies.

\section{References}

Bastick, Z and Mallet, M (2021). Double Lockdown: The Effects of Digital Exclusion on Undocumented Immigrants during the COVID-19 Pandemic. Available at:

https://ssrn.com/abstract=3883432

Charmaz K (2014). Constructing Grounded Theory. SAGE.

Connor, P., Passel, J. S., \& Krogstad, J. M. (2019). How European and U.S. unauthorized immigrant populations compare. Pew Research Center.

De Genova N. (2013) Spectacles of migrant 'illegality': the scene of exclusion, the obscene of inclusion. Ethnic and Racial Studies, 36:7.

Gonzales, A. L. (2017). Disadvantaged minorities' use of the Internet to expand their social networks. Communication Research, 44(4).

Guberek T, McDonald A, Simioni S, et al. (2018) Keeping a low profile? Technology, risk and privacy among undocumented immigrants. Proceedings of the $2018 \mathrm{CHI}$ Conference on Human Factors in Computing Systems.

Helsper, E. J. (2021). The Digital Disconnect: The Social Causes and Consequences of Digital Inequalities. Sage. 
Kaufmann, K. (2018). Navigating a new life: Syrian refugees and their smartphones in Vienna. Information, Communication \& Society, 21(6).

Lamont, M. (2018). "Addressing Recognition Gaps: Destigmatization and the Reduction of Inequality." American Sociological Review 83 (3).

Mallet, M. L., Calvo, R., \& Waters, M. C. (2017). "I Don't Belong Anymore":

Undocumented Latino Immigrants Encounter Social Services in the United States. Hispanic Journal of Behavioral Sciences, 39(3).

Mezzadra, S., Neilson, B. (2013). Border as Method, or, the Multiplication of Labor. Durham, NC: Duke University Press.

Newell BC, Gomez R and Guajardo VE (2016) Information seeking, technology use, and vulnerability among migrants at the United States-Mexico border. The Information Society, 32(3).

Pearce, K. E., Gonzales, A., \& Foucault Welles, B. (2020). Introduction: Marginality and Social Media. Social Media + Society, 6(3).

Wall, M., Otis Campbell, M., \& Janbek, D. (2017). Syrian refugees and information precarity. New Media \& Society, 19(2). 